\title{
The August 17, 1999 Izmit, Turkey, earthquake: slip distribution from dislocation modeling of DInSAR and surface offset
}

\author{
Salvatore Stramondo $\left({ }^{1}\right)$, Francesca R. Cinti $\left({ }^{1}\right)$, Michele Dragoni $\left({ }^{2}\right)$, Stefano Salvi $\left({ }^{1}\right)$ \\ and Stefano Santini $\left({ }^{3}\right)$ \\ (1) Istituto Nazionale di Geofisica e Vulcanologia, Roma, Italy \\ (2) Dipartimento di Fisica, Università di Bologna, Italy \\ $\left.{ }^{3}\right)$ Istituto di Fisica, Università di Urbino, Italy
}

\begin{abstract}
We show the results of application of Differential SAR Interferometry to the $M_{W} 7.4$, August 17, 1999, Izmit earthquake, Western Turkey. The differential interferogram is obtained using an interferometric ERS2 ascending pair with a time interval of 35 days (August 13th - September 17th). The fringe pattern clearly defines the coseismic displacement field extended in an area of about $100 \mathrm{~km} \mathrm{~N}-\mathrm{S}$ and $120 \mathrm{~km} \mathrm{E-W.} \mathrm{The} \mathrm{analysis} \mathrm{of} \mathrm{the} \mathrm{interferogram}$ shows the right-lateral strike-slip movement on the activated section of the North Anatolian fault system. The maximum SAR-detected displacement ranges between $117.6 \mathrm{~cm}$ and $134.4 \mathrm{~cm}$ in the proximity of Gölcük. We invert SAR data for uniform dislocation on a single fault plane using a Montecarlo procedure, with the aim of testing a large set of a priori possible asperity distributions on the fault. We then use a forward modeling approach to evaluate the slip variability for the dislocation using additional constraints as surface offsets and seismicity distribution: in this case we allow unit cells to undergo different values of slip in order to refine the initial dislocation model. Misfits between SAR data and modeled slant range displacements are generally low for all our models $(\sim 12 \mathrm{~cm})$. Our results indicate that slip is concentrated in the central-western part of the fault, in the upper 10-15 $\mathrm{km}$, tapering to the fault tips. For the Izmit case, we note that a well constrained fault model can be obtained only integrating DInSAR data with additional observations. This is mainly due to an undersampling of the displacement field by DInSAR, caused by decorrelation and lack of image data.
\end{abstract}

Key words 1999 Izmit earthquake - Differential SAR Interferometry - coseismic displacement field Montecarlo method - asperity distribution

\section{Introduction}

On August 17, 1999, Western Turkey was shaken by a destructive, $M_{W} 7.4$ earthquake. The event struck the highly developed urban and

Mailing address: Dr. Stefano Santini, Istituto di Fisica, Università di Urbino, Via S. Chiara 27, 61029 Urbino (PS), Italy; e-mail: santini@fis.uniurb.it industrialized area surrounding the Gulf of Izmit (Marmara Sea) and east of Adapazari (fig. 1). The mainshock originated on the northern strand of the North-Anatolian fault system, approximately $9 \mathrm{~km}$ southeast of the city of Izmit, at a depth of $16-18 \mathrm{~km}$. The focal solution shows a right-lateral strike-slip movement on the fault (Barka, 1999; Toksöz et al., 1999). The Izmit event was accompanied by about $120 \mathrm{~km}$ of surface rupture. The western limit of the rupture observed on land is in Gölcük and proceeds offshore in the Marmara Sea. Eastward, the breakage goes as far as Akyazi maintaining an E-W strike, then turns to $\sim$ ENE toward Düzce 


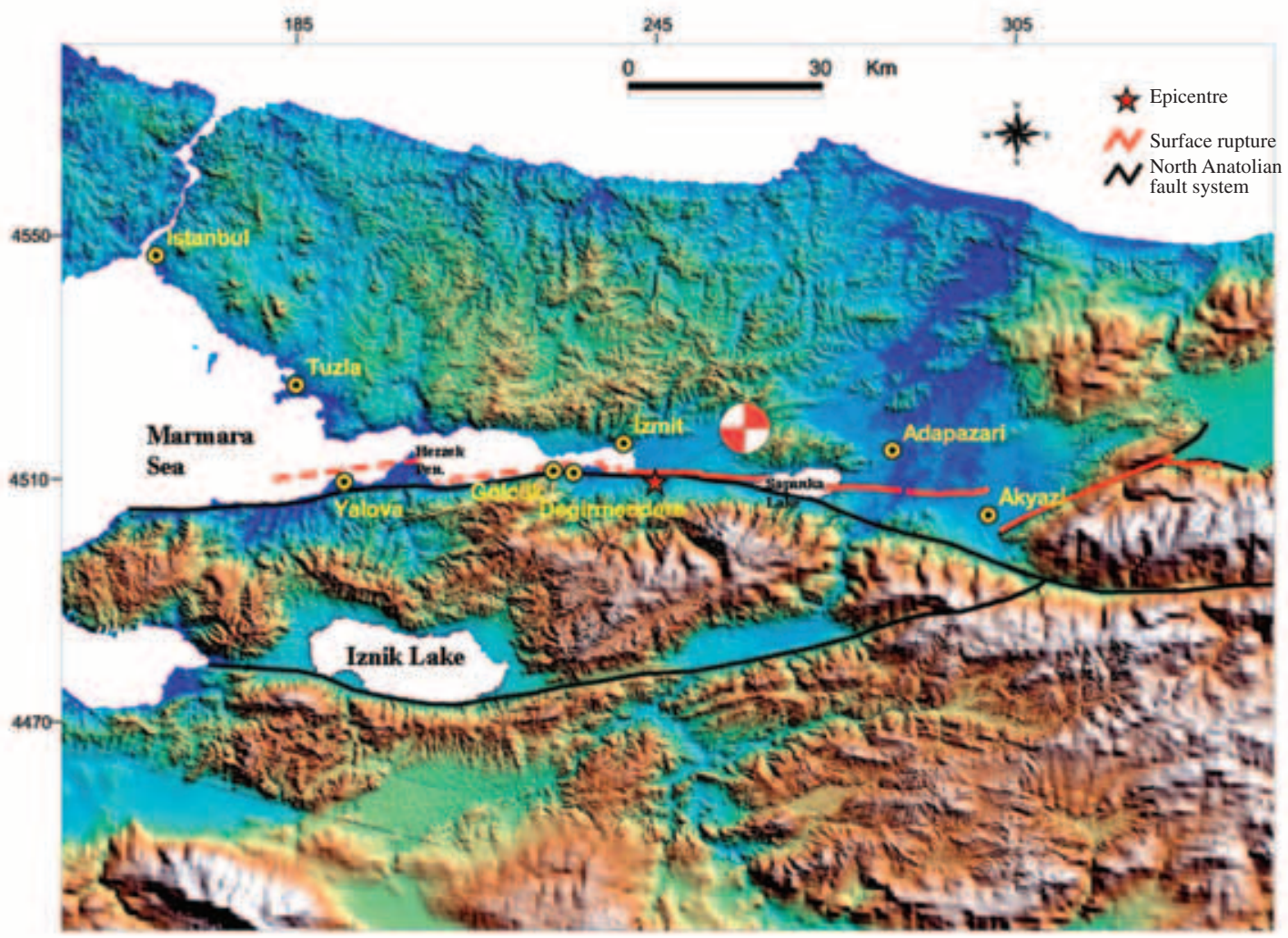

Fig. 1. Location and HCMT focal mechanism of the Izmit earthquake (17 August, 1999). The North Anatolian fault system and the surface rupture (dashed when offshore) (U.S. Geological Survey, 1999; IPGP web site, 1999) are indicated.

(fig. 1), the change in direction being marked by a gap in the surface displacement. The surface rupture, although continuous, shows a certain slip variability: maximum offsets of 4-5 m (Gölcük, E of Sapanka Lake), and an average of about 2.5 m (Barka, 1999; U.S. Geological Survey, 1999 and references therein)

We analyze the information relative to this seismic event derived from the application of the Differential SAR Interferometry (DInSAR) technique and discuss the significance of the fringe pattern with respect to the rupture mechanism. Unlike other point based (GPS), or line based (levelling) geodetic techniques, DInSAR is an image based technique which allows the spatial deformation pattern associated with an earthquake to be mapped at high resolution (see DInSAR theory and applications in Massonnet and Feigl, 1998 and references therein). This characteristic of DInSAR data is particularly favourable to develop well constrained dislocation models sensitive even to local slip inhomogeneities (Peltzer et al., 1994).

We quantify the maximum ERS-SAR displacement and invert the DInSAR data for a uniform slip dislocation using a Montecarlo procedure; SAR data are used in order to constrain the geometry of the dislocation surface. To this aim, an asperity model is employed, where the fault plane is divided into a large number of square asperity units which can slip by a constant amount or remain locked. We then start from this model 
to evaluate the slip distribution on the fault, using additional constraints and a forward modeling procedure.

The DInSAR data of the August 17, 1999, Izmit earthquake have already been presented and discussed in previous works (Delouis et al., 2000; Reilinger et al., 2000; Wright et al., 2001) with the aim of inverting the details of the seismic source. However, these studies suffer from the typical problem of data inversion, notably that they fail to clarify the effective constrains that the data impose on the inverted parameters. In this work, the distribution of asperities (or slip) on the fault plane is found using only the fault geometry, the geodetic data and the seismic moment related to the 1999 Izmit earthquake.

\section{The DInSAR data}

We selected an ERS 2 ascending pair, with an altitude of ambiguity $h_{a}$ (i.e. the altitude difference corresponding to a phase change of $2 \pi$ ) of $144 \mathrm{~m}$. The two images span 35 days (August 13th-September 17th, 1999), the minimum interval between two overpasses of the same ERS satellite on a specific area. The topographic phase contribution was subtracted using an interferometric DEM (courtesy of E. Fielding). Differential interferometry is more sensitive to vertical than to horizontal movements (the mean state vectors are 0.38 east, -0.08 north, 0.92 up, for ascending orbits and for Turkey region latitude). However, the Izmit strike slip fault has the best geometric setting to detect horizontal displacement with DInSAR. In fact, the ground projection of the satellite line-of-sight (slant range) being about parallel to the E-W fault, the displacement component on the slant range is maximized (Peltzer et al., 1994).

The differential interferogram (fig. 2) shows the surface coseismic displacement extending on both sides of the fault and covering a wide area, about $120 \mathrm{~km} \mathrm{E-W}$ and $100 \mathrm{~km} \mathrm{~N}-\mathrm{S}$. At large scale, fringes are parallel to the fault, showing variable gradient whose maximum is located west of the epicenter and converging towards the fault trace about $15 \mathrm{~km}$ west of the city of Gölcük (fig. 2). This general setting indicates that large displacement shown by the interferogram occurs in the western part of the fault. This observation seems to be in agreement with the high offsets measured on land that reaches $4.5 \mathrm{~m}$ in Gölcük before the fault enters the Marmara Sea. The concentric pattern on the shorelines of the Marmara Sea suggests the continuation of the rupture offshore for at least $20 \mathrm{~km}$.

The satellite-to-ground distance between the two image acquisitions increases north of the surface rupture and decreases to the south (fig. $2)$. This is in agreement with the right lateral kinematics of the fault. We first estimated the maximum measured range change based on the number of fringes observed at both sides of the fault in the proximity of Gölcük (fig. 2). We counted about 27-30 fringes in the northern side and 15-18 fringes in the southern side, each fringe representing a slant range displacement of $2.8 \mathrm{~cm}$. Note that for most of the fault extent in the near range of the fault SAR data are missing due to de-correlation (Marmara Sea and Sapanka Lake) and/or excessive deformation gradient. We manually unwrapped the phase starting from the fringes closer to the fault trace, along the $\mathrm{E}$ coast of the Izmit Gulf, assuming a surface offset of $3.4 \mathrm{~m}$ in this area (U.S. Geological Survey, 1999; IPGP web site, 1999), a pure right lateral slip and E-W direction of the fault to project the slip vector onto the satellite line of sight. We assume that the uncertainty associated with our unwrapping procedure is two fringes.

The interferogram is perturbed by atmospheric artifacts that can affect the propagation of the SAR signal (Massonnet and Feigl, 1998; Reilinger et al., 2000). For the Izmit interferograms, Reilinger et al. (2000) attribute differences of 3-4 $\mathrm{cm}$ between GPS and DInSAR displacements to changes in the atmospheric conditions between the two ERS image acquisitions. They claim these variations should occur over a spatial wavelength shorter than the distance between the GPS stations $(\sim 10 \mathrm{~km})$. Indeed, considerable moisture variations (water vapor is the most important parameter affecting tropospheric path delays in radar images, Zebker et al., 1997) can occur even on $1 \mathrm{~km}$ scale in case of strong tropospheric turbulence (Weck- 


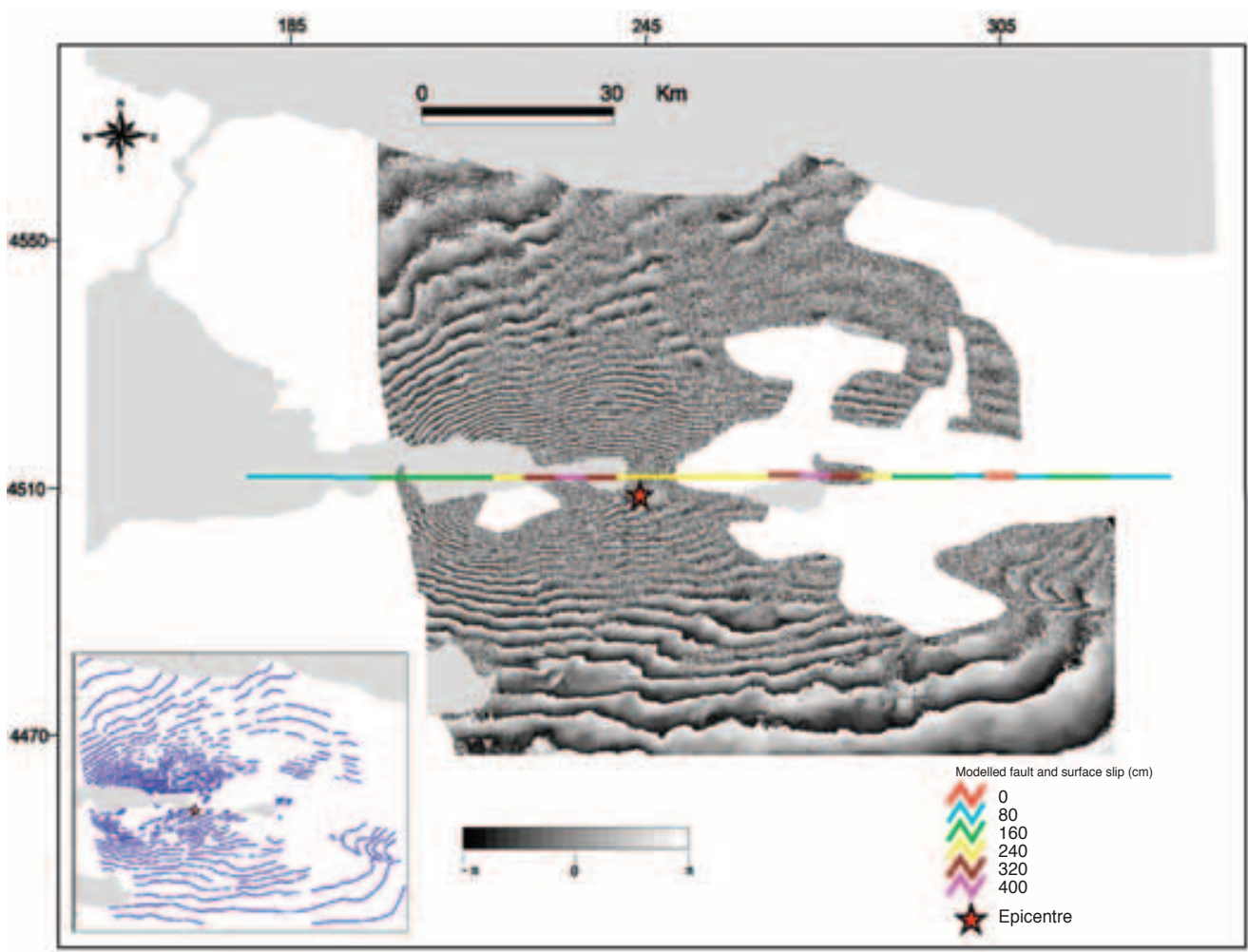

Fig. 2. ERS2 co-seismic differential interferogram. Fringes show the displacement field associated with the Izmit earthquake. The fault trace and the surface offsets (U.S. Geological Survey, 1999 and Barka, 1999) of the dislocation models in fig. 3b-d are shown. Fringe contours (blue lines) retrieved from the interferogram are in the inset. Each line indicates a surface movement of $2.8 \mathrm{~cm}$ onto the satellite line of sight.

werth et al., 1997), with relative humidity variations of several tens $\%$, giving rise to phase shifts of 1-2 cycles over distances of kilometers (Hanssen and Fejit, 1996). Over longer wavelengths though $(30-50 \mathrm{~km})$, the changes in relative humidity are usually smaller and the SAR phase shifts expected are of the order of a few cycles (Hanssen and Fejit, 1996). In our interferograms we do not see strong signs of tropospheric turbulence (in fact the interferogram difference shows only long wavelength residuals), therefore, assuming that only minor relative humidity variations have occurred over the scenes, we estimate a maximum atmospheric phase shift over the entire scene of 2 fringes.

\section{SAR data inversion by the Montecarlo method}

Let us consider an elastic, homogeneous and isotropic half-space, occupying the region $x_{3} \leq 0$ in a Cartesian coordinate system, and assume that the fault is a rectangular surface intersecting the Earth's surface with a dip angle $\delta$. The fault is strike-slip, right-lateral, and is made of 216 square asperity units. We assume that the Lamè constants are equal (Poisson solid) and calculated according to PREM (Dziewonski and Anderson, 1981): $\lambda=\mu=4.5 \times 10^{10} \mathrm{~Pa}$. In the case of a rectangular dislocation, the displacement field at the Earth's surface can be obtained by available analytical solutions (Okada, 1985). 
Table I. Source parameters used and rms values obtained for fault models in fig. 3a-d. For all models: Strike = $90^{\circ}$, Dip $=87^{\circ} \mathrm{S}$, Rake $=180^{\circ}$.

\begin{tabular}{cccccc}
\hline \hline Model no. & Length & Width & Slip & rms & Geodetic moment \\
\hline $3 \mathrm{a}$ & $120 \mathrm{~km}$ & $20-25 \mathrm{~km}$ & $1.6 \mathrm{~m}$ & $12.8 \mathrm{~cm}$ & $1.95 \times 10^{20} \mathrm{~N} \cdot \mathrm{m}$ \\
$3 \mathrm{~b}$ & $135 \mathrm{~km}$ & $20-25 \mathrm{~km}$ & $0.4-4.0 \mathrm{~m}$ & $11.9 \mathrm{~cm}$ & $1.95 \times 10^{20} \mathrm{~N} \cdot \mathrm{m}$ \\
$3 \mathrm{c}$ & $150 \mathrm{~km}$ & $20-25 \mathrm{~km}$ & $0.4-4.0 \mathrm{~m}$ & $11.8 \mathrm{~cm}$ & $1.95 \times 10^{20} \mathrm{~N} \cdot \mathrm{m}$ \\
$3 \mathrm{~d}$ & $150 \mathrm{~km}$ & $20-25 \mathrm{~km}$ & $0.4-4.0 \mathrm{~m}$ & $11.9 \mathrm{~cm}$ & $2.04 \times 10^{20} \mathrm{~N} \cdot \mathrm{m}$ \\
\hline
\end{tabular}

We set up a Montecarlo method (Metropolis and Ulam, 1949) with the aim of testing the performances of a large set of a priori random asperity distributions on the fault plane. Due to computing time constraints, we assumed a uniform slip on the fault $(\mathrm{U}=1.6 \mathrm{~m})$. For the same reason, we decided to approximate the Izmit earthquake rupture with a single fault surface whose parameters were defined on the basis of earthquake HCMT focal parameters (www.seismology.harvard.edu/), tectonic studies (Barka, 1997, 1999; U.S. Geological Survey, 1999; IPGP web site, 1999), and seismicity studies (Özalaybey et al., 2002). Our model fault surface is oriented $\mathrm{E}-\mathrm{W}$, dipping $87^{\circ}$ to the south, $180 \mathrm{~km}$ long, $30 \mathrm{~km}$ deep (fig. 3a-d). In our simulations, the depth of the dislocation bottom is variable $(20 \leq D \leq 25 \mathrm{~km})$.

Due to inhomogeneity of friction on faults, dislocation surfaces have usually irregular shapes. In order to take this into account, we assumed that the fault rupture is the consequence of the failure of a large number of small square asperity units (table I; fig. 3a-d). From the solution for a square dislocation, it is easy to obtain the analytical solution for any dislocation with a polygonal contour. As a consequence, it is possible to model the effect of dislocations with any shape by employing suitably small asperity units (e.g., Dragoni, 1988; Santini et al., 2000).

For our inversion, we used asperity units of $5 \times 5 \mathrm{~km}$. Failure of such asperity would correspond to a magnitude $M_{W}=6$ earthquake (the order of magnitude of the largest aftershocks of the Izmit sequence) for the unit dislocation, using the constant slip of $1.6 \mathrm{~m}$ (Kasahara, 1981). Assuming a seismic moment $M_{0}=1.95 \times 10^{20} \mathrm{~N} \cdot \mathrm{m}$ (Reilinger et al., 2000), we

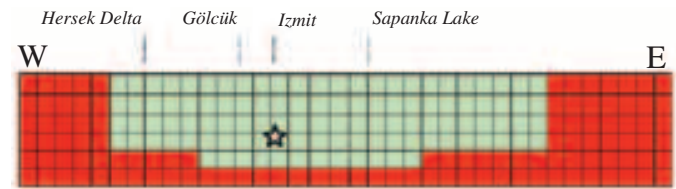

(a)

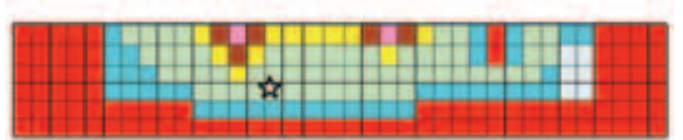

(b)

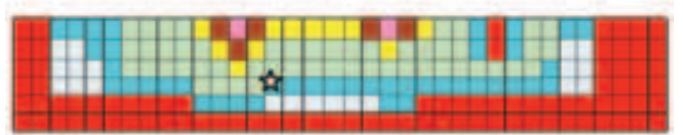

(C)

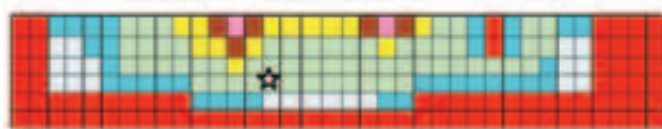

Slip=0.0 meters
(asserity unit)

Fig. 3a-d. Slip distributions for our dislocation models; each asperity unit is $5 \times 5 \mathrm{~km}$. a) Montecarlo inversion of DInSAR data with a uniform slip assumption $(\mathrm{U}=1.6 \mathrm{~m})$; b-d) Slip distributions from forward modeling of SAR and fault surface offsets (see text for explanation).

can model the dislocation area on the fault with $n=108$ unit cells.

We generated a set of 25000 random slip distributions, and we employed the symbol $u_{3, k}^{p}$ to indicate the vertical displacement predicted 
by the model at the generic $k$-th point at the Earth's surface. It is given by a sum over the $n$ square asperity units

$$
u_{3, k}^{p}=\sum_{j=1}^{n} u_{3, j}^{p} .
$$

In order to compare the displacement values predicted by the model with the observed values (SAR), we considered a square grid covering the Earth's surface in the fault region. The grid side is equal to $120 \mathrm{~km}$ and the distance from each point of the grid to one of the surrounding points is equal to $6 \mathrm{~km}$, implying that the total number of points is $N=21 \times 21=441$. We indicate the observed values of vertical displacement at the $k$-th point of the Earth's surface by the symbol $u_{3, k}^{o}$. The $\chi^{2}$ value is calculated for each slip distribution according to the formula

$$
\chi^{2}=N^{-1} \sum_{k=1}^{N} \frac{\left(u_{3, k}^{o}-u_{3, k}^{p}\right)^{2}}{\sigma_{k}^{o}}
$$

where $\sigma_{k}^{o}$ is the standard deviation of the observations.

In order to find the best shape of the dislocation surface, we chose the slip distribution having the smallest $\chi^{2}$ value. When we considered a variable slip on this surface, in the set of 25000 distributions generated by Montecarlo method, we retained as acceptable the subset of slip distributions, corresponding to $1 \%$ of the total number, having the smallest $\chi^{2}$ values. For them there is at least a $99 \%$ probability of finding a worse solution.

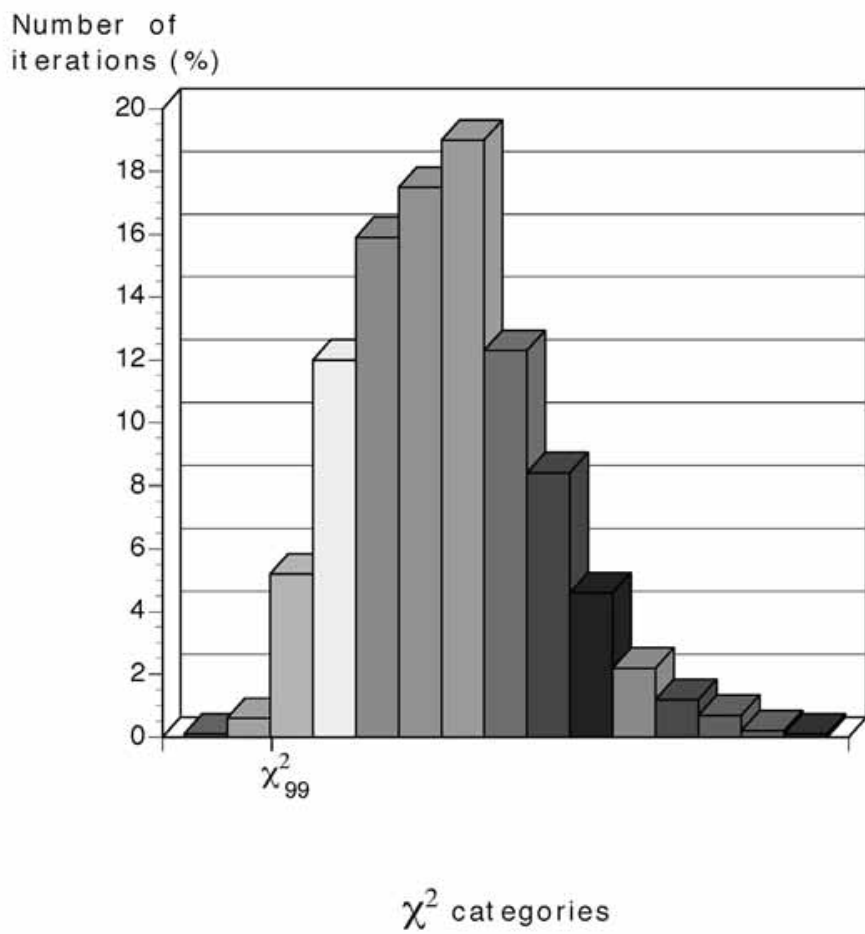

cat egory values
$\square<0.19$
$\square \quad 0.19-0.25$
$\square \quad 0.25-0.31$
$\square \quad 0.31-0.37$
$\square \quad 0.37-0.43$
$\square 0.43-0.50$
$\square 0.50-0.56$
$\square 0.56-0.62$
$\square 0.62-0.68$
$\square 0.68-0.75$
$\square 0.75-0.81$
$\square 0.81-0.87$
$\square 0.87-0.93$
$\square 0.93-1.00$
$\square>1.00$

Fig. 4. Distribution of $\chi^{2}$ values obtained from the Montecarlo simulations. The histogram shows which is the percentage of iterations in which a given value of $\chi^{2}$ is found. 


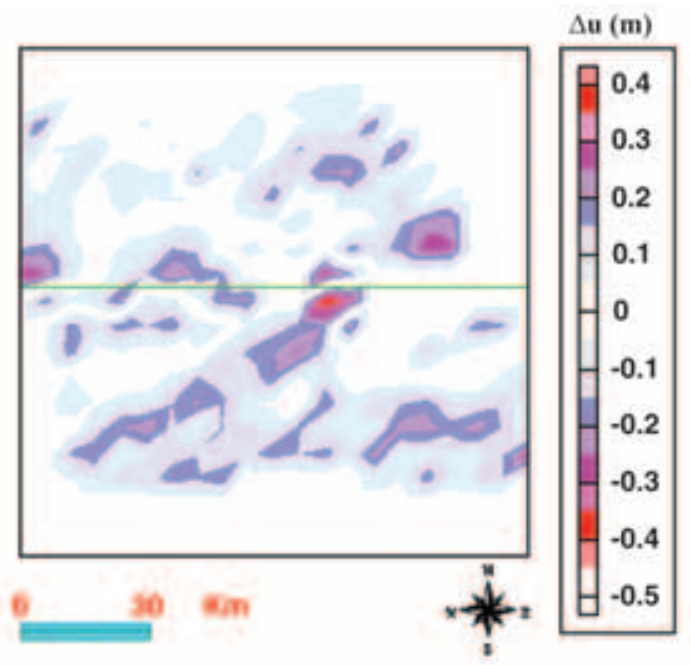

Fig. 5. Misfit $\left(\Delta u=u_{3, k}^{o}-u_{3 k}^{p}\right)$ relative to the fault model 3a, produced by the dislocation with a uniform slip equal to $1.6 \mathrm{~m}$. The green line is the modeled fault trace.

We defined $\chi_{99}^{2}$ the minimum of $\chi^{2}$ values associated with $1 \%$ of better distributions: in our case $\chi_{99}^{2}=0.25$ (fig. 4). In the subset, we retained as the best solution the one for which the slip is a function as smooth as possible of the position on the fault.

In this way, we used the DInSAR detailed spatial sampling of the slant range displacement to constrain the shape of the dislocation and to minimize the model uncertainties due to the noisy and/or missing DInSAR information. To account for the atmospheric phase shifts, uncorrected orbital effects, and unwrapping uncertainty, we assumed $\mathrm{a} \pm 2$ fringes uncertainty of the SAR observations, so that $\sigma_{k}^{o}=11.2 \mathrm{~cm}$.

Using this inversion procedure our best fit model was obtained with a minimum $\chi^{2}-$ test value equal to 0.15 . The inverted shape of dislocation is shown in fig. $3 \mathrm{a}$ and the misfit between observed data and model data is shown in fig. 5 .

\section{Forward modeling of slip distribution}

We used a forward modeling approach to infer the actual slip distribution over the dis- location area as determined in the previous section for the uniform slip (fig. 3a). The DInSAR data set, although yielding a high resolution representation of the displacement field, does not cover the entire extent of the earthquake rupture, due to image decorrelation along the fault trace and in the eastern fault zone. We therefore used all other available constraints to model the variable slip on the fault, in particular the published data on the surface fault displacements (Barka, 1999; U.S. Geological Survey, 1999; IPGP web site, 1999), and the aftershock distribution in the few days following the mainshock (Özalaybey et al., 2002).

Constraints to all our tests were the total geodetic moment equal to the seismic moment, and the shape of the dislocation, maintained as close as possible to fig. 3a. Considering the surface displacement data (fig. 3a-d) as additional constraints to the model in fig. 3a, we noted that the Montecarlo inversion of DInSAR data yields a dislocation length shorter than the rupture length observed in the field of about $15 \mathrm{~km}$ (figs. 2 and 3a-d) according to the surface displacement data. An asperity (zero dislocation) is present in the eastern part of the fault (figs. 1 and $3 b$ ), where a fault bending exists (from E-W to SW-NE); this feature was not detected by the Montecarlo inversion. The cause of these discrepancies is presumably due to the poor coverage of DInSAR data in the eastern half of the ruptured area (fig. 2).

Our next models incorporated the surface offsets (fig. 2). These data constrain exactly the dislocation of the first layer (0-5 km) of our model, while the slip on the deeper patches is imposed to be gradually decreasing with depth. This trend was already observed in other fault models (Reilinger et al., 2000; Delouis et al., 2000). We also increased the length of the dislocation surface to account for $\sim 0.8 \mathrm{~m}$ further surface displacement observed in the easternmost $15 \mathrm{~km}$ of the fault trace (fig. 3a-d). For the westernmost $25 \mathrm{~km}$ of the dislocation surface, the fault trace is hidden under the Marmara Sea; as an initial attempt to our forward modelling, we imposed here a slip of $1.6 \mathrm{~m}$ at the surface, decreasing towards the deepest part of the fault tip to $0.8 \mathrm{~m}$ (fig. $3 \mathrm{~b}$ ). The rms of residuals with the DInSAR data for the fault model in fig. $3 \mathrm{~b}$ is $11.9 \mathrm{~cm}$; the highest misfits (up to $41 \mathrm{~cm}$ ) are 
(a)

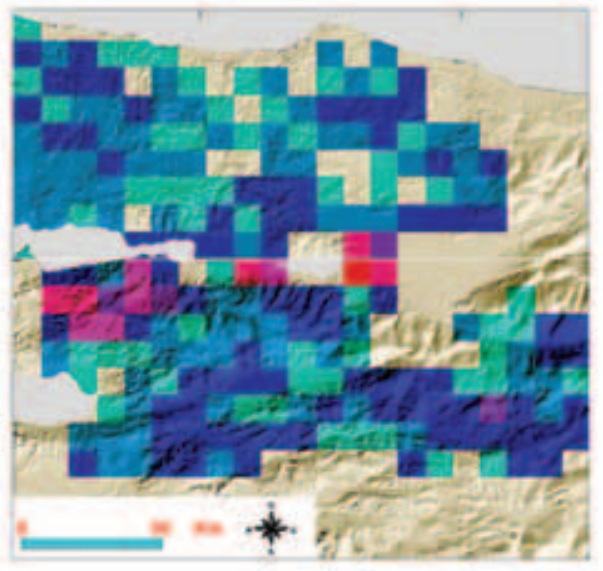

(b)

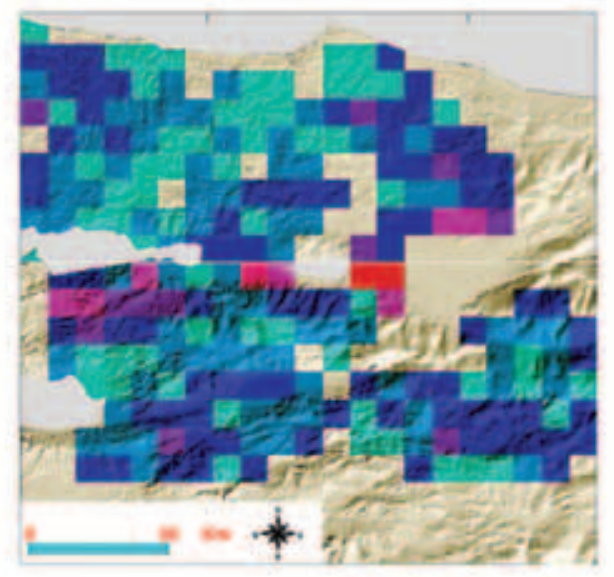

(C)

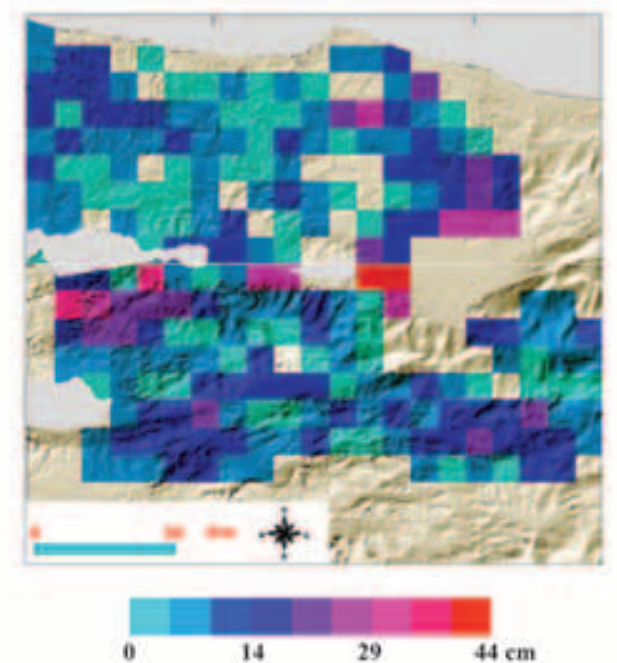

located in the near field, within $5 \mathrm{~km}$ from the fault trace (fig. 6a).

The previous model, while in agreement with the observed surface displacements, still underestimates the fault length. In fact, the model fault ends $10 \mathrm{~km}$ west of the Hersek peninsula (fig. 1), whereas the distribution of aftershocks which occurred shortly after the mainshock (Özalaybey et al., 2002) clearly shows a further $\mathrm{E}-\mathrm{W}$ continuation of the ruptured zone for about 15-20 km into the Marmara Sea. We use these data to constrain a new model where the total fault length is $150 \mathrm{~km}$ (i.e. further increasing the dislocation surface length of $15 \mathrm{~km}$ to the W). We performed some tests to determine the slip distribution in this area and found that, while west of the Hersek peninsula the slip tapers to the fault tip, the presence of an $\mathrm{L}=20 \times \mathrm{W}=15 \mathrm{~km}$ patch of at least $1.6 \mathrm{~m}$-slip in the area between Gölcük and the Hersek peninsula (fig. 3c) is required to obtain a smaller misfit. To maintain the geodetic moment but enlarge the dislocation area, we imposed a more gradual tapering of the slip at depth in the central part of the fault.

This model is shown in fig. 3c; its misfits with the DInSAR data are shown in fig. $6 \mathrm{~b}$. Beyond the high values along the fault trace, which are constant in all models, the misfits of model $3 \mathrm{c}$ show an improvement with respect to model $3 \mathrm{~b}$ (its rms is $11.8 \mathrm{~cm}$ ), except in the $\mathrm{E}$ part of the displacement field.

Our final attempt was to model the slip distribution dropping the fixed moment constraint and introducing a few variations trying to reduce the highest residuals of model $3 \mathrm{c}$. Performing a limited number of tests, we were not able to reach a significant improvement of the previous model. $\mathrm{A} \sim 5 \%$ geodetic moment increase in model $3 \mathrm{~d}$, corresponds to a slight rms increase with respect to model $3 \mathrm{c}(11.9 \mathrm{~cm})$. Figure $6 \mathrm{c}$ shows the model $3 \mathrm{~d}$ residuals; a general increase in maximum misfits in the NE and $\mathrm{W}$ part of the fault is observed.

Fig. 6a-c. Misfits relative to the fault models $3 b$ (a), $3 c$ (b), $3 \mathrm{~d}$ (c). Misfits have been obtained for each $6 \times 6 \mathrm{~km}$ cell, after masking of DInSAR data for decorrelated areas. The white line is the modeled fault trace. 


\section{Discussion and conclusions}

Our modeling procedure allowed us to: i) model the general dislocation shape through Montecarlo inversion of SAR data only; ii) evaluate the distribution of slip over the rupture plane using additional constraints from geological and seismicity data. Assuming first a uniform slip, we obtained a best fit of surface coseismic deformation for a dislocation surface with an irregular shape. The agreement with observations was improved by redistributing the fault slip on the dislocation surface.

We note that our uniform slip model yields rather low misfits with $\mathrm{SAR}$ data $(\mathrm{rms}=12.8$ $\mathrm{cm}$ ); this is surprising, considering the strong variability of slip inferred by all studies (Reilinger et al., 2000; Delois et al., 2000; Wright et al., 2001). We attribute this behaviour to undersampling of the displacement field by the SAR data (we estimate that SAR data are available for only about $60 \%$ of the actual displacement field) and possibly to a smoothing effect due to uncorrected orbital errors and long wavelength atmospheric perturbations.

The small differences in the average residuals among all our variable slip models $(0.1 \mathrm{~cm})$ suggest that the data at our disposal are unable to give full details of the slip distribution. In any case, considering the single fault approximation, we obtain results for the most part in agreement with published studies performed also using different data sets (Reilinger et al., 2000; Delouis et al., 2000; Wright et al., 2001). The depth of dislocation varies between 20 and $25 \mathrm{~km}$, and is maximum in the fault western-central segment; the largest slip values are concentrated in the central part, with two maxima in the Gölcük and east Sapanka segments. Most of the large misfits in fig. 6a-c are concentrated along the fault trace, although these misfit values are biased by the presence, in each of the $6 \times 6 \mathrm{~km}$ discrete map units, of a large percentage of decorrelation noise, i.e. underestimation of actual displacement. Other large misfits $(\sim 30 \mathrm{~cm})$ are present south of the Hersek peninsula in all our models. The absence of surface faulting in this area and our large misfit values can be explained if, at some point between Gölcük and Hersek, the rupture actually steps north, so that its surface expression is hidden under the Marmara sea. On the east side of the fault we also observe high misfits $(\sim 25 \mathrm{~cm})$; the reason is probably the difference between our approximated model fault (E-W) and the direction of the actual fault segment (SWNE, fig. 1). Notwithstanding the model assumptions and the single fault approximation, for most of the areas showing a well defined fringe pattern we obtain misfits smaller than $10 \mathrm{~cm}$ (fig. 6a-c).

The application of SAR interferometry to the retrieval of the Izmit earthquake source parameters has shown once more that for an improved earthquake monitoring strategy in non-arid environments, more effective SAR data acquisition policies must be implemented. Decorrelation due to rapid surface changes can be reduced using a shorter revisiting time as well as a longer radar wavelength (L band). Atmospheric effects should be more accurately estimated, e.g., using independent meteorological data, to assess the data set consistency; their correction could be attempted only if a large number of interferometric data sets are available and/or if simultaneous images from other sensors allow for atmospheric parameters retrieval.

\section{Acknowledgements}

We wish to thank the European Space Agency that delivered the set of ERS SAR images, making possible the accomplishment of this work. Special thanks go to Eric Fielding (University of Oxford, U.K.) for providing the DEM. We are also grateful to Alessandro Amato for his useful comments and to Enzo Boschi for his encouragement. The Diapason software, by CNES (Toulouse, France), was used for the ERS image interferometric processing. This research was partly supported by the Italian Space Agency, contracts No. I/R/138/ 00 and $\mathrm{I} / \mathrm{R} / 174 / 01$.

\section{REFERENCES}

BARKA, A. (1997): Active Tectonics of Northwestern Anatolia: The Marmara Poly Project, ETH, Zurich, 55-87.

BARKA, A. (1999): The 17 August 1999 Izmit earthquake, Science, 285, 1858-1859.

Delouis, B., P. Lundgren, J. SALICHON and D. GiARDinI (2000): Joint inversion of InSAR and teleseismic data for the slip history of the 1999 Izmit (Turkey) earthquake, 
Geophys. Res. Lett., 27, 3389-3392.

DRAGONI, M. (1988): Role of geodetic measurements in the detection of fault asperities, in Proceedings Third Int. Conf. on the WEGENER/MEDLAS Project, edited by P. BALDI and S. ZERBINI, Bologna, 129-146.

DZIEWONSKI, A.M. and D.L. ANDERSON (1981): PREM, Phys. Earth Planet. Inter., 25, 297-356.

HANSSEN, R. and A. FEIJT (1996): A first quantitative evaluation of atmospheric effects on SAR interferometry, in Proceedings Fringe Workshop on SAR Interferometry, ESA SP-406.

IPGP web site (1999): Rupture mapping, field observations and measurements on Duzce rupture, beaufix.ipgp.jussieu.Fr/ inst/org/tecto.

KASAHARA, K. (1981): Earthquake Mechanics (Cambridge University Press, Cambridge), pp. 248.

MASSONNET, D. and K.L. FEIGL (1998): Radar interferometry and its application to changes in the earth's surface, Rev. Geophys., 36 (4), 441-500.

Metropolis, N. and S.M. Ulam (1949): The Montecarlo method, J. Am. Statist. Assoc., 44, 335-341.

OKADA, Y. (1985): Surface deformation due to shear and tensile faults in a half-space, Bull. Seismol. Soc. Am., 75, 1135-1154.

ÖZalaybey, S., M. ERgin, M. AKTAR, C. Tapirdamaz, F. BIÇMEN and A. YÖRÜK (2002): The 1999 Izmit earthquake sequence in Turkey: seismological and tectonic aspects, Bull. Seismol. Soc. Am., 92, 376-386.

Peltzer, G., K.W. HudNuT and K.L. Feigl (1994): Analysis of coseismic displacement gradients using radar interferometry: new insights into the Landers earthquake, J. Geophys. Res., 99 (B11), 971-981.
REILINGER, R.E., S. ERGINTAV, R. BÜRGMANN, S. MCCLUSKY, O. LENK, A. BARKA, O. GURKAN, L. HEARN, K.L. FEIGL, R. CAKMAK, B. AKTUG, H. OZENER and M.N. TÖKSOZ (2000): Coseismic and postseismic fault slip for the 17 August 1999 , M 7.5, Izmit, Turkey earthquake, Science, 289, 1519-1524.

SANTINI, S., A. PIOMBO and M. DRAGONI (2000): Ground displacement in a fault zone in the presence of asperities, Boll. Geofis. Teor. Appl., 41, 95-110.

TOKsÖZ, M.N., R.E. REILINGER, C.G. DOLL, A.A. BARKA and N. YALCIN (1999): Izmit (Turkey) earthquake of 17 August 1999: first report, Seism. Res. Lett., 70, 669-679.

U.S. GeOlogical SURVEY (1999): Implications for earthquake risk reduction in the United States from the Kocaeli, Turkey, earthquake of August 17, edited by S.J. KROPSCHOT, Circular 1193, pp. 64.

WECKWERTH, T. M., J.W. WILSON, R.M. WAKIMOTO and N.A. CROOK (1997): Horizontal convective rolls: determining the environmental conditions supporting their existence and characteristics, Mon. Weather Rev., 125, 505-526.

Wright, T., E. FIELDING and B. PARSONS (2001): Triggered slip: observations of the 17 August 1999 Izmit (Turkey) earthquake using radar interferometry, Geophys. Res. Lett., 28, 1079-1082.

ZebKer, H.A., P.A. Rosen and S. Hensley (1997): Atmospheric effects in interferometric synthetic aperture radar surface deformation and topographic maps, J. Geophys. Res, 102, 7547-7563.

(received February 22, 2002; accepted July 15,2002 ) 